\title{
What Did Kuwait Learn from Its Participation in TIMSS Study? An Exploratory Case Study from Senior Supervisors' Perspectives
}

\author{
Fatimah Alhashem ${ }^{1} \&$ Ali Alkandari ${ }^{2}$ \\ ${ }^{1}$ National Center for Educational Development (NCED), Kuwait \\ ${ }^{1}$ College of Education, Kuwait University, Kuwait \\ Correspondence: Fatimah Alhashem, National Center for Educational Development (NCED), Kuwait. E-mail: \\ falhashem80@gmail.com
}

$\begin{array}{lr}\text { Received: October 17, } 2015 & \text { Accepted: November 10, } 2015 \quad \text { Online Published: November 20, } 2015 \\ \text { doi:10.5539/ass.v11n27p298 } & \text { URL: http://dx.doi.org/10.5539/ass.v11n27p298 }\end{array}$

\begin{abstract}
The low performance of The Trends of Mathematics and Science Study (TIMSS) results were investigated in depth through interviews with math and science supervisors from the Ministry of Education in Kuwait. A qualitative approach was employed to consider the factors that may affect TIMSS results in the past and understand the reasons of TIMSS results. The outcome of this study was limited to the perspectives of science and math supervisors who participated or worked in the TIMSS study. Their participation in TIMSS was positive even if the results of the study were not because it helped initiate reform in curriculum, assessment, and quality of teaching. However, the participants expressed concerns and variables that need to be aware of in order to perform better not only in TIMSS but also in science and math education in general.
\end{abstract}

Keywords: TIMSS, supervisors, reform

\section{Introduction}

The Trends of Mathematics and Science Study (TIMSS) is part of a series of studies by The International Association for the Evaluation of Educational Achievement (IEA). TMISS study is a worldwide research project that takes place every four years. It began in 1995, when fourth and eighth grades were tested (Mullis, Martin, Gonzalez, \& Chrostowski, 2004).

Kuwait, like many other countries, joined the TIMSS study based on a recommendation from the World Bank in 1995 (Wiseman, Alromi, \& Alshumrani, 2014). The World Bank advised the stakeholders at The Ministry of Education (MOE) to participate, as the reform process took place in the education system of Kuwait (Winokur, 2014; Wiseman, Alromi, \& Alshumrani, 2014). There were many reasons to participate: the structure of TIMSS helps in providing data about trends in mathematics and science achievement over time; it assesses the knowledge and skills around the world; and it allows researchers to collect extensive background information about the quantity, quality; and content of teaching (Mullis et al., 2004). It also provides international benchmarks that may assist policy makers in identifying the comparative strengths and weaknesses of their educational system. Therefore, the findings from TIMSS can be used

- $\quad$ to inform education policy about their status compared to other countries;

- $\quad$ to improve teaching and learning in mathematics and science for pupils;

- $\quad$ to develop and improve the educational system's capacity to engage in national strategies for educational monitoring and improvement; and finally,

- $\quad$ as a stimulus factor for more reforming processes to improve education (Mullis et al., 2004).

Based on advice from the World Bank, stakeholders at the MOE wanted to explore the performances of their students in both math and science in TIMSS, but the results were not keen nor enthusiastic. Kuwait participated in the study in 1995, 2007, and 2011. Unfortunately, the scores were below average every time Kuwait participated. Consequently, massive reform calls and plans took place in the MOE with regards to curriculum, assessments, and other development plans (Alqabas Newspaper, 2013; Wiseman, Alromi, \& Alshumrani, 2014).

The results of TIMSS were discussed as top topics in the media, in the news, at educational conferences, in schools, and in colleges (Alqabas Newspaper, 2013; Wiseman, Alromi, \& Alshumrani, 2014). The aim of this 
study was to investigate the case of TIMSS from the perspective of supervisors. The reason for selecting supervisors was because of their role at MOE in general and their role in TIMSS specifically. Supervisors in Kuwait look over teachers, schools, curricula and assessments. Yet the supervisors were in charge of and involved in many activities during TIMSS (Alkandari 2006, MOE, 2009; National Report of Kuwait, 2008). They were responsible for writing the report, establishing awareness, and grading the tests. Therefore, instead of focusing on participants such as teachers, parents, and their students, we wanted to know the role of the mediator or the facilitators in TIMSS. Our goal and the outcome from this paper was to investigate, in depth, the reason Kuwait is at the bottom of the list in TIMSS in both math and science.

Thus, our research question was, "Among all of the years of participation in TIMSS, why do students still achieve low scores compared to other countries?" This study explores and investigates the problem from supervisors' perspectives.

\section{Literature Review}

\subsection{The Structure of TIMSS}

The structure of TIMSS not only looks into the performance of the students in the test but also investigates the surrounding factors that may affect their performance in the tests (Mullis et al., 2004; Mullis, Martin, Foy, \& Arora, 2012). The contextual framework and background questionnaires of TIMSS consider the relationship between student's achievements based on certain factors. Therefore, TIMSS examines these factors: curriculum and benchmarks, schools, teachers and their preparations, classroom activities, and students. The data are collected through surveys given to school leaders, teachers, parents, and their students.

The first factor in the TIMSS contextual framework, the development of curriculum, takes into account the viewpoint of society: which role the education system serves, students' needs, and what is important to be taught (Mullis et al., 2012). Next, TIMSS views school as an institution that serves in implementing the goals of the curriculum by focusing on certain indictors (Mullis et al., 2012).

Next, TIMSS also look for indicators regard the quality of school such as "organization of the school; school goals; roles of the school principal; resources to support mathematics and science learning; parental involvement; and a disciplined school environment." (Mullis, Martin, Ruddock, O'Sullivan, \& Preuschoff, 2009, pp. 9-14). The third factor in TIMSS, and the primary one, was the teacher. The TIMSS study views teachers as the agents that implement the curriculum, and their practices in the class affect student learning (Mullis et al., 2012). Thus, TIMSS focuses on certain issues regarding teachers' qualifications: teachers' preparation programs; hiring and recruitment, including certifications, induction, and professional development; and teaching styles and assignments (Mullis et al., 2009). In addition to teacher practices, classroom activities are also considered; such as how much of the curriculum is being implemented in class and which educational approaches are being used. Finally, the TIMSS study examines students and their backgrounds, their attitudes towards learning, and their performance in math and science (Mullis et al., 2009). The TIMSS study values all of the previous factors by using sets of questionnaires for each party and an assessment tool, using multiple-choice and short answer questions, to examine students' performances in math and science.

\subsection{TIMSS Study in Kuwait}

Kuwait has invested considerable amounts of its oil wealth into developing education (National Report of Kuwait, 2008). The proportion of spending on education in Kuwait was $14.8 \%$ of the gross domestic product in 2012. However, despite the educational efforts and significant financial investments made by the MOE, the quality of education is still questionable and concerns different stakeholders due to the modest results in different global studies such as TIMSS and PIRLS (National Institute of Education, Singapore [NIE] Report, 2013; Wiseman, Alromi, \& Alshumrani, 2014). These results pushed for more reform in the education system, with a focus on the quality of the system. There are numerous challenges to face, from managing the system to developing, improving, and reforming it. Participation in TIMSS came across the MOE plans while they were establishing reforming in the system with cooperation from The World Bank (Wiseman, Alromi, \& Alshumrani, 2014; NIE Report, 2014). In 1994, 2007, and 2011, the MOE was responsible for conducting the TIMSS study. The MOE formed committees of specialists with the collaboration of professors from Kuwait University, The Public Authority for Applied Education and Training, and supervisors (National Center for Educational Development [NCED], n.d.; Wiseman, Alromi, \& Alshumrani, 2014). The upcoming TIMSS in 2015 will be under the supervision of NCED, with the cooperation of MOE from the supervisory department, Kuwait University, and The Public Authority for Applied Education and Training (NCED, n.d.). Currently, NCED is working on establishing awareness in the field and among the community, including parents and students (NCED, n. d.). 
During the past few years, after participating in the TIMSS study, MOE's efforts have focused on improving the quality of education (Wiseman, Alromi, \& Alshumrani, 2014; NIE Report, 2013; NCED, n.d.). Among the countries that participated in TIMSS in 2011, Kuwaiti students in Grade 4 have scored lower than most. According to the results of the TIMSS study, announced in 2012, Kuwait ranked 48 out of 342 (IEA, n.d.; NIE Report, 2014). By choosing the top three countries of the performance, Figure 1 shows the overall result of the State of Kuwait in 2011 among the top six countries in the world.

A regional comparison was not fulfilling either. By using 10 selected countries in the region, as shown in Figure 2, Bahrain in first place at 436, and Kuwait in eighth place, ahead of Morocco and Yemen.

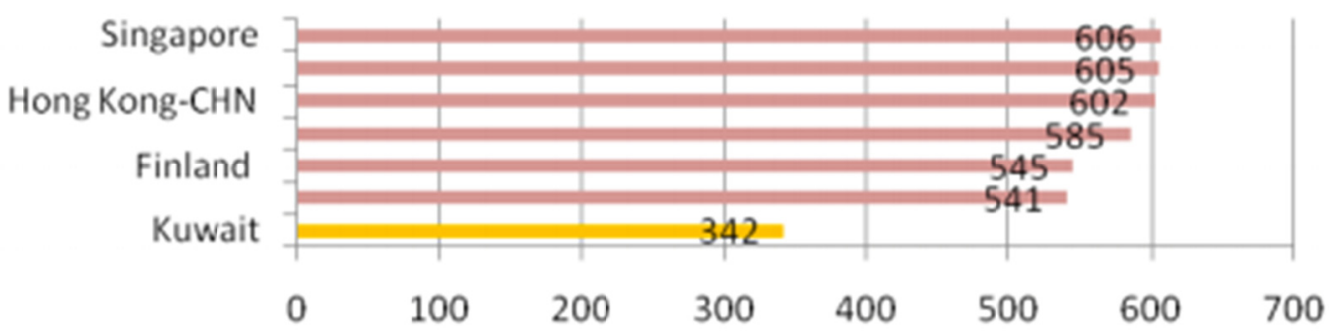

Figure 1. TIMSS 2011 results for grade 4 for seven selected countries

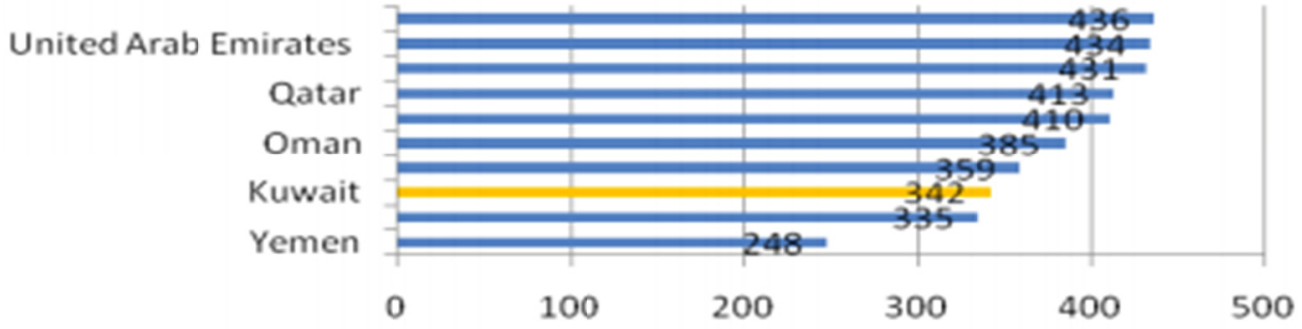

Figure 2. TIMSS 2011 results for grade 4 for selected countries in the region

The results implied the need to make an effort in Kuwait to increase student's performance in science and math. Students' performance depends on several factors, such as a well-developed curriculum, qualified teachers, a sustaining learning environment, and supporting parents (Barber, Mourshed, \& Whelan, 2007; NIE Report, 2013). Thus, many sectors, departments, and managers must get involved to improve of students' achievement. In a centralized system, we wanted to know which sector was most involved with the study of TIMSS and what did they do.

Kuwait has a centralized education system, where power and decision-making are concentrated in a single unit (Al Sharaf, 2006; Winokur, 2014). In the MOE, decision-making remains within few people. Assistant undersecretaries, district heads, managers, and supervisors in the MOE may start as a teacher and, through promotions and experience, reach an administrative or technical position (National Report of Kuwait, 2008). Because our focus was on supervisors, we elaborated more about their roles and duties.

A supervisor job's description can be defined as someone who oversees or directs the performance and development of teachers in the school context while practicing teaching (MOE, 2009; National Report of Kuwait, 2008). Supervisors in Kuwait play so many roles and are responsible for so many duties regard implementing curriculum (MOE, 2009; National Report of Kuwait, 2008). The supervisory department is under the assistant undersecretary's office, where each subject has senior supervisors, a first supervisor for each school district, and a group of supervisors underneath the first one (MOE, 2009; National Report of Kuwait, 2008). There are 148 science supervisors and 151 mathematics supervisors each of them supervises from 50 to 60 teachers (MOE, 2009; National Report of Kuwait, 2008). The main duties for the supervisory role are monitoring education quality, making assessments, overseeing teacher development, and developing the curriculum (MOE, 2009; National Report of Kuwait, 2008). The critical role of supervisors in the system (Figure 3) must be explored and questioned, because of their involvement in assessment, teacher development, and curriculum, which again has a deep impact on students' performance. 


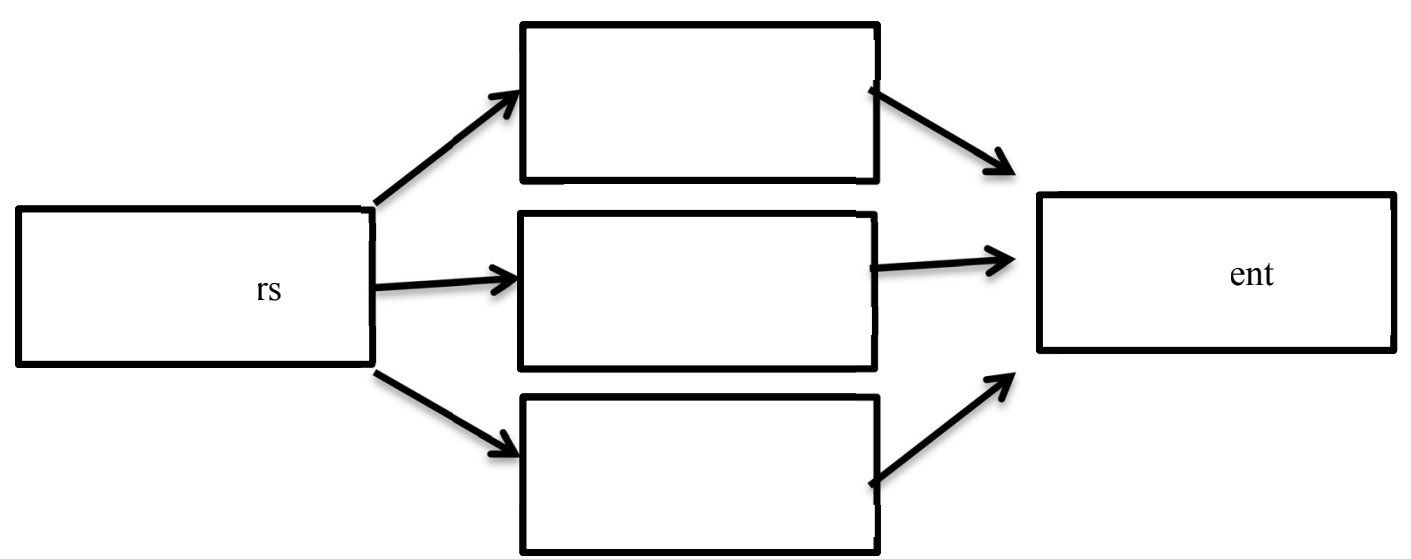

Figure 3. Supervisors Roles in Kuwait

Table 1 shows the role of supervisors and senior supervisors (MOE, 2009). They may also get involved in other voluntary or mandatory activities or tasks assigned by the assistant undersecretary of general education. First supervisors and some supervisors were involved in the TIMSS study in terms of attending the research coordinator meetings for the study and being involved in preparing the field, explaining the study, grading, and writing the final reports.

Table 1. Role of Supervisors in Kuwait

Supervisors

1. Draw a general plan for the academic field and supervise its implementation and evaluation.

2. Mentor the academic field technicians.

3. Supervise student teachers and novice teachers and follow up with them.

4. Write a vision to achieve based on certain objectives.

5. Participate in writing recommendations to improve curriculum.

6. Write annual reports to the undersecretary for public education about the reality of the academic field in all respects and submit proposals for development.

7. Identify the needs of the academic field of books and references and educational techniques in collaboration with professional mentors.

8. Draw the general plan of activities for the academic field of support and supervision of the implementation and evaluation.

9. Participate with the selection committee's professional mentors, educational department heads, and new teachers.

10. Assess the results of exams from different educational areas and monitor the students' academic achievement.

11. Propose training programs needed by field of study.

The TIMSS study revealed the current curriculum, assessment techniques, and teaching methods in science and mathematics. According to Barber, Mourshed, and Whelan (2007) and Al-Manabri, Al-Sharhan, Elbeheri, Jasem, and Everatt (2013), the current mathematics program is largely dependent on memorizing definitions, theories, performance algorithms, and other routine procedures. The science tests are mainly consisted from simple facts, with some scientific principles to explain phenomena; and therefore the results of this assessment indicate that expectations for the performance of students in Kuwait are low (Alkandari, 2006). Next, many teachers continue to use of traditional methods that inhibit active inquiry and learning process may have an effect on students' performance in math and science (Al-Manabri et al., 2013).

The NIE Report (2013) implied the need for an assessment system designed to stimulate the upper skills of thinking. The purpose of the current assessment is to determine whether students have achieved the goals of the 
curriculum. It has been observed that the tests do not represent a challenge to the students, especially with respect to complex issues or to applying knowledge and skills. Thus, the current examination system allows the majority - if not everyone - to move to the advanced stages of learning but misleading to reality (Al-Manabri et al., 2013; Barber, Mourshed, \& Whelan, 2007).

Next, the NIE Report (2013) noted the absence of quality teaching among many teachers at MOE. The MOE did not request any type of certifications prior or during teaching. Also, there has been a shortage of training or professional development for teachers due to the limitations prescribed for the training budget, which was estimated at 400 thousand dinars annually for all employees, including teachers, administrators, and staff in 2013 (NIE Report, 2013). In addition, cultural habits, such as caring for family and considering teaching as female job, perhaps enable many motivational factors for teachers to improve their knowledge about the subject and pedagogical skills (NIE Report, 2013; Winokur, 2014).

In conclusion, Since supervisors are responsible for developing teachers, implementing curriculum, and assessing students, therefore, supervisors to find out from their perspective what is going on in the field and what changes have been made regarding improving and reforming science and math education based on TIMSS results.

\section{Method}

In order to understand the situation while TIMSS was taking place and the reasons that students' performance may have been affected, the perspectives of the first senior supervisors and supervisors who participated effectively in the TIMSS study was important. Supervisors, as mentioned in the literature review, were involved in many tasks regarding students' performance. Thus, we used a qualitative approach, utilizing an in-depth interview technique for all first supervisors from all school districts, followed by supervisors. The rationale for using this design was to understand the challenges facing education systems in Kuwait. The case study would help in generating deeper insights on the specific needs for improving learning outcomes and enhancing performance.

\subsection{Instrument}

The guideline for developing the structure of the interview questions was the conceptual framework of TIMSS. The TIMSS study investigated the factors that may have an impact on students' performance. We wanted to ask supervisors questions about their perspectives in terms of the context of teaching, curriculum, assessment, and teachers. In addition to that, we asked them about TIMSS itself and their perceptive about it and their own experience (see Table 2). Therefore, the interview questions were divided into five main sections, and were based on the structure of TIMSS and the awareness of TIMSS. After developing the interview questions, a specialist in qualitative methods reviewed them to ensure validity. Then we translated the questions into Arabic before conducting the research.

Table 2. Interview questions

\begin{tabular}{|c|c|}
\hline & Questions \\
\hline A & Context/Teaching methods \\
\hline 1 & $\begin{array}{l}\text { - What are the problems/obstacles that science/math educators face while teaching in school and their classes? } \\
\text { - What are the teaching methodologies used mainly in the classrooms? Is the teacher active, passive, or students } \\
\text { centred? }\end{array}$ \\
\hline & - $\quad$ Are the teaching methods centred on the teacher or the student? Who is more active in the class? \\
\hline 2 & $\begin{array}{l}\text { - From your experience working at MOE, how would you see/view/evaluate the students in } 4^{\text {th }} \text { and } 8^{\text {th }} \text { grade in math } \\
\text { (concepts/knowledge/skills). (Probe) what are their strengths and weakness? } \\
\text { - What do labs/classrooms miss to help students understand science/math? } \\
\text { - What do you think of the school environment (classrooms and labs from an educational viewpoint)? }\end{array}$ \\
\hline B & Curriculum/Standards and Benchmark \\
\hline 3 & $\begin{array}{l}\text { - What are you expecting from teaching science/math? What are the goals/objectives from teaching science/math? } \\
\text { What is the reason for teaching science/math? } \\
\text { - Do you think the curriculum is serving the needs? What is missing in our curriculum? How would you differ the } \\
\text { needs of TIMSS from our curriculum? } \\
\text { - Describe the curriculum of science and math (the concept of the whole curriculum or/and the content } \\
\text { knowledge). Is it achieving the goals and objectives of the subject? Why or why not? }\end{array}$ \\
\hline 4 & - $\quad$ How is the science department (supervisors) at MOE filling the gap between the local and international \\
\hline
\end{tabular}


benchmark if so?

- What is the science curriculum missing? What about the standards implementation? How are we going to ally with the international ones?

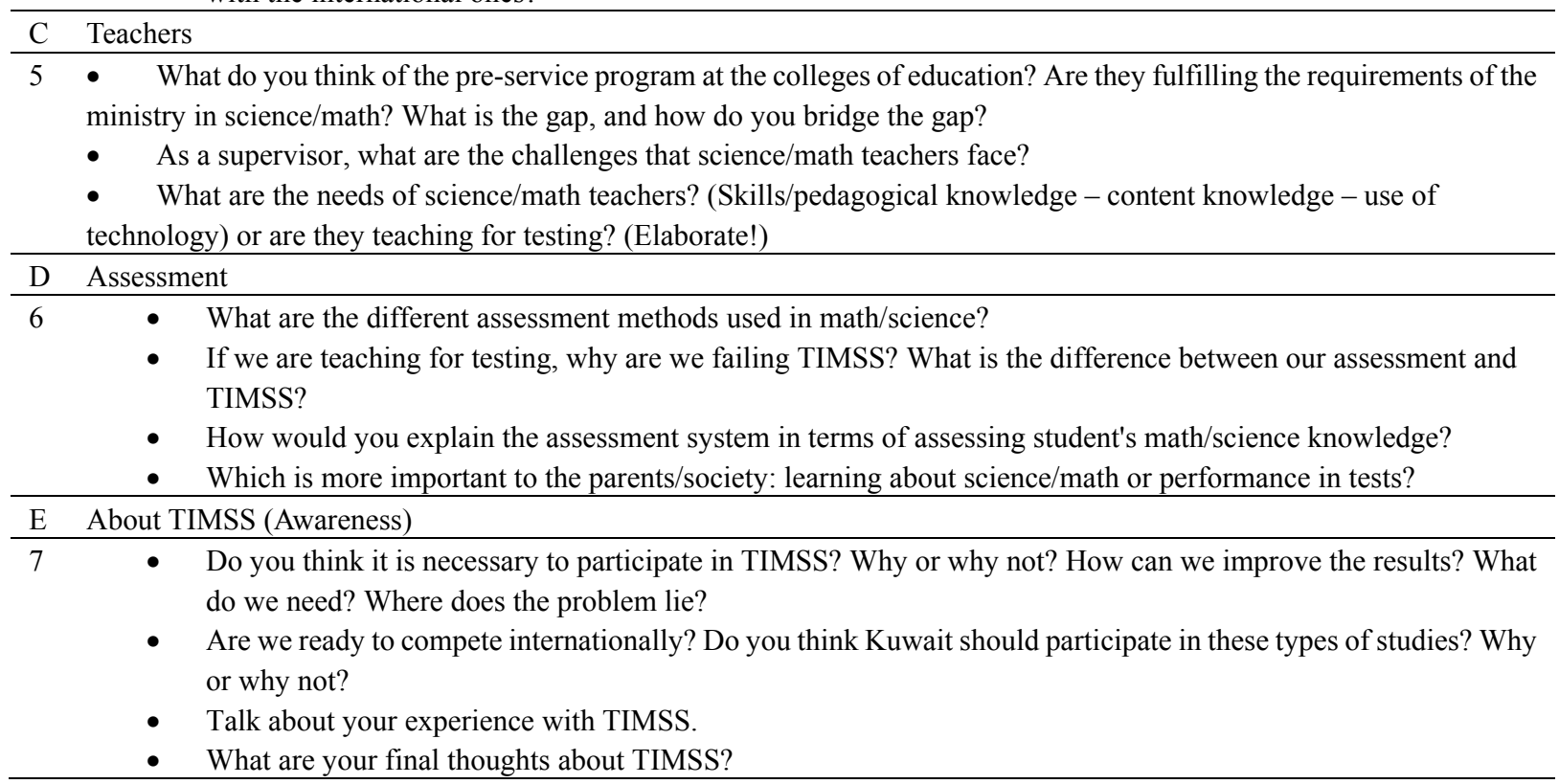

\subsection{Participants}

Our population in general was limited to the supervisory department at the MOE. The MOE has six school districts in the six counties of Kuwait. Each district has a senior supervisor, and six to seven supervisors work under their administration (MOE, 2014; National Report of Kuwait, 2008). For the purpose of confidentiality of the supervisors, we decided not to provide any information that can identify the senior supervisors, supervisors, or the school district that they belong to.

In general, the proportion of females was higher than males. The years of experience for senior supervisors in the field of education was not less than 20 years, and for supervisors it was not less than 15 years. Therefore, in the results section, we will only refer to the "he/she" identity of our participants to assure that they are not being identified.

\subsection{Procedure}

After the interview structure was developed. We started our data collection in late December in 2014 to January of 2015. We contacted the senior supervisors in both science and math for the six school districts in Kuwait: a total of 12 senior supervisors. The senior supervisors provided us with contact information for the supervisors in their districts whom were in involved in TIMSS. We contacted seven science supervisors and six math supervisors, for a total of thirteen. Therefore, the total number of participants in this study was 25 supervisors from both science and math subjects (see Table 3).

Table 3. Participants

\begin{tabular}{cccc}
\hline District & Science Senior Supervisors & Math Senior Supervisors & Supervisors \\
\hline Asmah & 1 & TIMSS research coordinator & 6 \\
Hawali & 1 & 1 & 4 \\
Mubark AlKabeer & 1 & 1 & 2 \\
Farwanyah & TIMSS research coordinator & 1 & 3 \\
AlAhamdi & 1 & 1 & 1 \\
Jahra & 1 & 1 & 1 \\
\hline
\end{tabular}


Interviews were conducted over the telephone, with duration of one and a half to two hours. We took detailed notes on respondent's answers. After that, the respondents' notes were translated, organized, and coded. We started to map the major concepts, factors, and evidence. For analysing the data, scheme-based analysis was employed. The major coding system will focus on the open coding procedure, using a grounded theory research design. Using this approach, the data were subjected to several stages of analysis, where emergent categories were anticipated to provide insight into the nature of the challenges and allow the use of evidence-based interpretations of the findings. Both researchers crossed code interviews for reliability. Last, the outcomes of supervisors' interviews were presented in the results.

\section{Results}

The results were divided based on the following: context of teaching math and science, the current curriculum, teaching, and assessment. In each section, we provided the most powerful quotes, and the main themes were found as we were analysed the data and translated the interviews. For the purpose of confidentiality, we only reported the responses very generally to keep the identity anonymous.

\subsection{The Teaching Context}

The teaching context varies between math and science. Both senior supervisors and supervisors of math reported that the teaching context is lacking from many shortages, and the sizes of the classrooms were not adequate for the number of the students. Most math senior supervisors and supervisors reported that even the equipment in math classes were not available for many teachers to demonstrate or "do math" while teaching certain concepts, such as geometry. They also reported that some schools were not using technology in classrooms, but some of them said that some school administrations, especially in girls' schools, were aided with technology, such as iPads. Three out of five math supervisors reported that some teachers purchased tools with their own money. Most of the math senior supervisors and supervisors mentioned that teachers are still applying the traditional method while teaching math. One of them said,

Our curriculum does not support teachers to apply math. The curriculum is very dense, and the time is very short, and you know we cannot miss important concepts. I cannot blame teachers; some of them try very hard, but still our students do not pay attention or lose focus because the teacher is always next to the white board. Again, even if the teacher wants to move around, it would be very hard for him/her to move because the classrooms are small and filled with students. The amount of students is reasonable, but the sizes of some new schools are too small. So I can confirm that many teachers are the centre of their classrooms due to the environment, lack of resources, and the structure of the math curriculum.

One of the senior supervisors reported that teachers try hard to use the exploration method while teaching math, but they usually go quickly with less participation from students because of the overloaded curriculum. Her perspective about the size of the classrooms was not very different from her colleagues in the other districts. Her elaboration reflected on most of the other participants in terms of school environment:

Principals are trying very hard to overcome the new small designs of schools. Nevertheless, still they cannot control other things due to the structure of the school. One dust storm can fill the school with dust and make the place unhealthy for the students. In addition, the schools are cold in winter and hot during autumn and toward the end of school year in May and June. I can summarize this by saying many schools but not all are missing the quality of safety.

Science classes on the other hand seemed to have fewer problems in terms of classroom size due to the availability of labs. However, they still have some concerns due to teacher practices. One senior supervisor said,

The ministry provided equipment and technology to support the science labs. We also have lab assistants to help prepare labs prior the class. In every school budget, a certain amount of cash is being spent for labs. The main problem will always remain with teachers who prefer to teach science using old, or let's say out-dated methods. You know, no matter how many tools we have, the traditional method is still dominating.

Another supervisor elaborated about the teaching method:

We have a problem with integrating the goals and the objectives into doing and practicing science. The lack of management is due to the teacher. Many of the violence problems among boys go back to the teacher. He does not allow them to work in class, which makes them feel bored and frustrated. We have a problem with managing students in class because we assume that they can understand science with a traditional style of teaching. 
The majority of perspectives about the school atmosphere were negative. Interviewers claimed that schools induce students to study for tests for all subjects, including math or science. The students are surrounded with people that want them to pass the test whether they understand the subject or not. Both science and math supervisors said that our teaching methods and systems are turning our students into passive learners. One of the science senior supervisors said, "Our students are smart, but the unfair system caused them to perform poorly."

\subsection{Curriculum}

The curriculum was the second set of questions in the interview. Supervisors revealed many issues regarding the math and science curriculum. Once we addressed the question about the curriculum, the first reaction we received from supervisors in general was the textbook. Then they expand their thoughts about goals, objectives, concepts, and everything relating to curriculum. The teaching methods and the assessment are all tied up to the textbook, which is considered the curriculum.

In general, recently, Kuwait began implementing the revised mathematics curriculum using new textbooks gradually, beginning with Grades 1-3 in the 2008-09 academic year, Grades 4-5 in 2009-10, Grades 6-7 in 2010-11, and Grades 8-9 in 2011-12. The science curriculum also has been under revisions in terms of books. As with mathematics, Kuwait began implementing a revised science curriculum with new textbooks gradually, beginning with Grades 1-3 in the 2008-09 academic year, Grades 4-5 in 2009-10, Grades 6-7 in 2010-11, and Grades 8-9 in 2011-12. The new curriculum contains the same basic concepts that existed in previous curricula, including international, structural, and cumulative concepts, but topics are presented in a new way, with deeper explorations of scientific facts and concepts.

First, the math senior supervisors and supervisors expressed their concerns about curriculum. The curriculum has endless topics and concepts that limit teachers to a few examples due to the shortage of time. The math senior supervisors and supervisors in different districts all agreed that the math curriculum is overloaded across all grades. They also believed in the importance of math as a core subject because it deals with logic and develops the students' thinking and their abilities to solve problems. In terms of TIMSS and the math curriculum, they expressed that the concepts of TIMSS do not differ much. However, they said that topics in the curriculum are overlapped. The description drawn about the math curriculum seemed that priorities and trivial topics are mixed together, which makes the curriculum long and overwhelming for both teachers and students. One senior supervisor said,

When we started TIMSS, we did not know about the nature of the study, but by the time we started figuring out the pattern. Therefore, we started adding TIMSS examples into our curriculum. Note that TIMSS is testing the understanding while we are still teaching for passing the tests....

Next, all math senior supervisors and supervisors stated that the curriculum is now changing towards meeting the international standards. Another supervisor reported,

We are now developing new curriculum, and we are working with NCED for TIMSS 2015. Nevertheless, I have to say that TIMSS does not represent the real performance of students...we are missing the awareness. We are not missing anything in our curriculum plan other than that it is too dense, and by the way we are working towards changing the curriculum to an advanced one.

Science shared some similarities with math when it comes to the curriculum, but they had some differences. The science senior supervisors expressed their concerns about the amount of hours per week for science class, as the curriculum has too many topics to be covered. Science in elementary and middle school has only three hours per week, and this amount of time is not enough in many cases to cover the overloaded curriculum. A senior supervisor said the following:

Our curriculum, or let's say textbooks, are very good, but because we teach for testing not for understanding, it limits the students' critical thinking. The situation is very complicated; the teachers don't want to change... the students wants to pass, and what we lose is skills and education. TIMSS asks students to think, while we ask them to memorize, so we did not prepare them when the curriculum was designed.

Another senior supervisor elaborated more about the role of their department. He explained the role of bridging the gap in terms of students' performance in science locally and internationally by developing better curriculum. He said,

We started an awareness campaign among supervisors. We wanted to investigate the needs among supervisors themselves. We realized that many supervisors did not leave their "teaching hats" they still think that they are teachers. They still cannot help in guiding teachers or assessing them. I believe TIMSS helped us look at what we need in terms of curriculum and us as supervisors to support the field. 
The science supervisors' responses were positive regarding the textbooks and curriculum but not the teaching methods or how the curriculum is being implemented. They claimed that the science curriculum has $60 \%$ of TIMSS concepts. One of the senior supervisors said about the curriculum,

Our curriculum is comprehensive and has many of the international concepts; we may have some issues such as adjusting some topics to our culture and environment. Our problems remain in the implementation part. Due to the absence of standards, the teacher ends up sticking to the textbook.

One of the science supervisors elaborated more about the curriculum. He expressed that the situation is too complicated and complex for the supervisory department to handle. Many others, from science supervisors to some math supervisors, said that same things. He said,

Their involvement from politicians in education was negative and much of the decisions politicians oppose the development of curriculum. In addition, there are many tenders of textbooks and that does not help curriculum, there are many benefits without considering the risks that will cost the education system in Kuwait very much. There are many decisions that have been made in the absence of us supervisors or at least a valid study in terms of curriculum.

\subsection{Teachers}

The perspectives about teachers were ramified. In general, supervisors expressed their concerns regarding teachers in terms of the following: teachers' practices, preparation programs in colleges, non-Kuwaiti teachers, recruitment system for teachers, and shortages of professional development. Most of the teachers have a bachelor degree; the two-diploma graduates began decreasing proportion of all disciplines after the MOE stopped hiring teachers with less than a college education degree. Any shortages of teachers, in science and math, will be filled by hiring foreign teachers from the Middle East. Mostly, the attrition and the turnover is higher among male teachers. The cultural perspectives is that the teaching profession is considered a female profession because it is stable with summer vacations. On the other side, supervisors expressed that men were not very motivated towards teaching math and science due to the cultural view and low payment compared to other fields in the market.

The next issue was the preparation programs at Kuwait University and PAEET. There was not an agreement of how well the programs of math or science in colleges in Kuwait. Some supervisors complained about the passive teaching programs when preparing teachers, while others said that the colleges of education prepare well-trained beginner teachers. Nevertheless, the worries were about the number of graduates and the proportion of the needs at MOE. The math supervisors expressed their worries from the decline in terms of graduates in math education programs at college in Kuwait. One of the senior supervisors said,

The newcomers from the math education colleges are very smart, but in many cases are shocked with the amount of work and they also get disappointed with the inequality in the system. For example, the promotion structure delays some subject like math, and we cannot do anything about it as supervisors, although we are assessing their performance. Besides, they are getting overloaded from the administration.

Regarding math teacher needs and how teachers are teaching students, she responded,

Well, many teachers need more training; we need more professional development, better workshops, and better instruction for them. Due to the lack of budget and time, we end up losing focus on this important issue. We also assume that once the teacher has a degree they can teach well. But that is not right. Let me explain! Many teachers don't know how to use assessment tools such as exams to even quizzes for their students because they were not trained, and most of the exams are being assigned from the district. In addition, there is a shortage of professional development at MOE. As supervisors, we cannot do everything. We cannot inspect, assess, support, and train teachers all the same time. We need fewer duties to focus more on teacher development. We only have sometimes two hours for training teachers in the field, while we need at least 38 hours of training for teachers.

The science supervisors' main concerns were the shortage of physics and chemistry teachers. In Kuwait, we only have three Kuwaiti male physics teachers, and the rest are not Kuwaiti. They expressed their concerns on how to build capacity while the advantages in the profession are not very attractive. They also showed their concerns regarding the quality of non-Kuwaiti teachers. Hiring foreigner teachers is missing the standards and the qualifications. Many foreigners do not know about the MOE system and have some cultural differences even if they are from the same region. Also, non-Kuwaiti teachers are paid less, which causes inequality and a lack of motivation. Teachers' needs did not differ from the math supervisors in terms of professional development and supporting teachers in the field. They elaborated more in terms of the teaching methods by expressing their 
concerns about the traditional way of teaching. A senior supervisor of science summarized her colleagues point of view by saying,

There is a degree of dissatisfaction about teaching as a profession, as there are, a large number of females joining the teaching profession because of their parents without having goals or visions regard their career.... The output of colleges of education is very passive in terms of preparation because they focus on the theoretical part of education but not the practical. There is only one semester of student teaching at the last year of college.... Regarding the teaching style, we still suffer from the teacher-centred style. We provided all the needs for teachers, from equipment to resources, but still few are applying and using them and do inquiry or interactive lessons, but the majority are not. They either lazy or do not know how.

\subsection{Assessment}

Regarding assessment, the concerns and problems discussed by the science and math supervisors were the following: negative parents' involvement, teaching for testing, and cheating. Most science and math exams focus on memorizing the facts. The supervisors were forced to limit the tests to the memorization level, leaving the understanding and critical questions outside the assessment system due to the political pressure and the parents' pressure; all they care for is passing the students to the next level.

In addition, the assessment structure prevents teacher from developing their formative assessment skills. The major proportion for grades are always left for summative tests, which keeps the cycle of teaching for testing active while teaching for understanding barely takes place in the system. Assessments are misleading the community; the memorization type of test prevents students from solve problems and applying what they have learned in class and in the assessment Therefore, this pressure of limiting the test questions to memorizing facts caused another problem in the assessment and evaluation system. Students will not take any test, or study seriously unless for grading or rewarding. The MOE assessment outcome is misleading and does not show or differentiates outstanding students. One of the supervisors in math explained the situation of the assessment:

Math needs to assess 20\% of student's knowledge, $70 \%$ of application and $10 \%$ of critical thinking, but we are not able to apply this structure of tests because it is very sensitive. We lost the authority, and much involvement by parents is negative. It does not really support student learning. At the same time, I cannot blame them for being very demanding of their children. You know the world became more complex and they want jobs for their kids. They do not even mind if their children cheat in the tests as long as they pass.

The science supervisor explained the reason for failing TIMSS, due to the carelessness among students and other things beyond the science curriculum. He said,

TIMSS was not taken seriously in the past; not just students by but also from teachers and supervisors. Besides, our system did not train teachers or students with critical questions.... I have to tell also that our students are having difficulty reading. The Arabic classes did not prepare our children to read independently. So do not expect our children to pass tests that they cannot comprehend.

\subsection{TIMSS Awareness}

The responds regarding the participation in TIMSS were very positive. Supervisors worked in TIMSS in different roles: two of them were research coordinators at TIMSS and others worked in translating, meeting with teachers, grading, and writing final reports about TIMSS. All the participants agreed about the importance of participation in TIMSS, and it was beneficial even with the low performance of students. The TIMSS study showed the errors in the system, the teaching style, student's motivation toward learning, the assessment, and curriculum. Since the first participation in TIMSS in 1994, the MOE started to reform curriculum and worked hard to use advanced textbooks that cover and share many international concepts in math and science. The reform did not hit the math and science subjects, but major things started to change. Other organizations and centres are now interested in contributing in this reform after TIMSS, such as NCED.

Supervisors also expressed their worries about their readiness to participate in international studies such as TIMSS. They said they are not ready but they still do not want to be isolated and decline from such studies. One of the math supervisors said the following:

Our students are smart, and I believe they can pass TIMSS if we train them to do such exams. We need more awareness among all parties in the MOE and the community. I think what we are doing is not enough. We do not want to be just ready for TIMSS: we want our children to have a good education.

The science supervisors shared the same views about the math but elaborated more about other issues:

We do not want to be separated from the world, and it was an external motivation for change. Nothing will 
stay the same, but sometime it takes a while for a community to catch up. We might not be ready after all of these years, but at least we did make many changes in the system. I think our problem is the fear that we are afraid to go forward. We want more involvement in TIMSS, not just grading and being facilitators; we are asking NCED to train us to become more aware and interactive in terms of the TIMSS study.

\section{Discussion and Conclusion}

Kuwait has participated in TIMSS three times and is going to participate in a few months in TIMSS 2015. The TIMSS 2011 results echoed a clear commitment to follow up on implementing focused measures to achieve success in advancing education. The study argued that reform initiatives in education are not limited to funding but extend to include adjustments to existing policies related to administrative operations, teacher quality and training, and the assessment and evaluations system at MOE. In this study, the focus was to look deep and investigate from supervisors' perspectives through a qualitative study about the poor performance of students in math and science.

In-depth interviews were conducted with supervisors and senior supervisors in science and math, and generalizations about the results are limited to the sample because small samples were chosen and a random sampling methods was not used. With in-depth interviews, we were able to provide valuable information for stakeholders and researchers who are interested in TIMSS and reforming the system in Kuwait. Supervisors were able to enrich the study with their field experience in curriculum, teachers, assessment, and participating in TIMSS. There were issues in every part that has an impact on student's performance; however, there were other factors that may affected the results of TIMSS. The tone of supervisors, in general, was passive. They seemed to have less authority and were more like reporters or inspectors about the field.

Their responses showed that the problem was beyond student achievement. The context, methods, and assessment did not fully provide the appropriate guidance for students to achieve. First, the curriculum is missing national standards to guide it, whereas TIMSS is based on international benchmarks and standards, so the comparison was like comparing oranges to apples. The curriculum at MOE is to teach and be able to finish textbooks while internationally many countries are teaching certain topics and concepts to meet a set of standards (NIE Report, 2014). In addition, supervisors kept talking about textbooks as a guide, not a tool to the curriculum, and some of them considered developing textbooks to be equivalent to developing curriculum. The curriculum is missing the standards, but MOE and NCED are working to develop national standards for teachers, curriculum, and school leadership (Winokur, 2014). The participation in TIMSS may cause or push the system toward the initiation of the standards.

Teaching styles and methods are still centred on teachers. There are factors that caused teachers to stick to the traditional methods. The overloaded curriculum, the massive amount on summative assessments and tests, and the absence of professional development for teachers are the main factors that cause teachers to teach science and math traditionally. Some supervisors pointed out that the local colleges of education share responsibility in preparing teachers. Based on the interviews, the foreign teachers were not as qualified as the system required. Many foreign teachers are teaching with basic levels, do not get enough training or professional development, and are paid less. With all three factors for recruiting foreigner teachers, we cannot set high expectations for them. Therefore, MOE may consider developing a better system for building capacity while maintaining quality in hiring teachers.

Yet the assessment method used at MOE seemed to be old and traditional. The teaching for testing approach prevents students from critical thinking, and the overloaded curriculum forces the summative assessment such as tests and quizzes to take place instead of other assessment methods. Students are becoming passive learners because of the huge amount of topics and tests. The system at MOE does not apply national exams to measure student performance, which may negatively affect students' performance in TIMSS. Also, the lack of awareness about the importance of TIMSS may benefit from further investigation. It was shown from the interviews that not all supervisors were fully aware of TIMSS, as a result, teachers, parents or students do not know about TIMSS.

Participation in TIMSS seemed to be the motivator for the system to move forward. However, the demands for making a difference in terms of the performance are many. It seemed that supervisors need more authority or at least a voice while making a decision for curriculum, assessment, and teacher development. However, the viewpoints and responses of supervisors about TIMSS may have some misconceptions too. They have the sense that TIMSS study is a competition where some countries loose or win, but TIMSS is a study that helps a certain country to identify their level based on certain criteria.

Lastly, any study that represents the community needs a marketing campaign to establish awareness and deliver 
the rationale behind it. Indeed, Kuwaiti performance in TIMSS was very low, but many did not know about TIMSS other than the results. The heads of science and math were not aware enough about TIMSS and standardized testing, which may indicate why our students were not scoring well. Thus, establishing awareness should take place throughout the system, including parents.

The outcome from this research is limited to the sample, and it may be carried on to wider researches quantitatively, but decision makers may want to consider these recommendations:

- Improve teacher training and preparation programs toward best practices in curriculum design and educational assessment with a focus on student-centred instruction that promotes the skills of logical thinking and creativity among students.

- Institute a system for professional development of in-service teachers and school leaders and to be up-to-date with the latest development of curricula and teaching methods as well as evaluation and leadership.

- Establish awareness among parents by asking them to participate, and guide their participation towards students learning rather than passing the test only.

- Collaborate with NCED in terms of the TIMSS study and other projects towards better education for all students.

- Prepare banks of questions along the lines of TIMSS questions to be distributed to schools. This could include a preparation of an experimental test includes all schools.

- Continue working on the current education reform policy to develop curricula taught at all academic levels and to ensure that instructional materials are properly designed to enhance critical thinking and problem solving skills. The ultimate goal is to encourage creativity and raise the level of student performance on international tests such as TIMSS and PIRLS.

\section{Recommendations for Future Studies}

There are many studies that can follow up this one and enrich the field, persuade stakeholders, and help in identifying the problem of low performance. The low performance in TIMSS is a complex matter and has many angles to be discovered. In this research, we limited the focus to the supervisory perspectives. This study is limited the voice of supervisors. We can utilize the outcome of this study to generate a study for teachers, parents, and students about their awareness of TIMSS and the current education for science and math.

\section{References}

Al Sharaf, A. (2006). New perspectives on teacher education in Kuwait. Journal of Education for Teaching, 32(1), 105-109. http://dx.doi.org/10.1080/02607470500511108

Alkandari, A. (2006). To what extent science education objectives are presented in science teachers' lesson plan in Kuwait schools. The Educational Journal, 80

Al-Manabri, M., Al-Sharhan, A., Elbeheri, G., Jasem, I. M., \& Everatt, J. (2013). Supporting teachers in inclusive practices: Collaboration between special and mainstream schools in Kuwait. Preventing School Failure: Alternative Education for Children and Youth, 57(3), 130-134. http://dx.doi.org/10.1080/1045988X. 2013.794325

Alqabas Newspaper. (2012, December 13). Kuwaiti Students in last place (text in Arabic).

Barber, M., Mourshed, M., \& Whelan, F. (2007). Improving education in the gulf. The McKinsey Quarterly, (special edition), 39-47.

Ministry of Education. (2009). Development of the education in the state of Kuwait. Kuwait, the administration of planning and training.

Mullis, I. V., Martin, M. O., Foy, P., \& Arora, A. (2012). TIMSS 2011 international results in mathematics. International Association for the Evaluation of Educational Achievement. Herengracht 487, Amsterdam, 1017 BT, The Netherlands.

Mullis, I. V., Martin, M. O., Gonzalez, E. J., \& Chrostowski, S. J. (2004). TIMSS 2003 international mathematics report: Findings from IEA's Trends in International Mathematics and Science Study at the fourth and eighth grades. TIMSS \& PIRLS International Study Center. Boston College, 140 Commonwealth Avenue, Chestnut Hill, MA 02467.

Mullis, I. V., Martin, M. O., Ruddock, G. J., O'Sullivan, C. Y., \& Preuschoff, C. (2009). TIMSS 2011 Assessment Frameworks. International Association for the Evaluation of Educational Achievement. Herengracht 487, 
Amsterdam, 1017 BT, The Netherlands.

National Centre for Educational Development. (n. d.). Retrieved February, 2014, from http://www.nced.edu.kw

National Institute of Education, Singapore Report. (2013). International conducts a diagnostic study of Kuwait's education system. Retrieved November, 2014, from http://www.nced.edu.kw

National Report of Kuwait. (2008). Development of education in the state of Kuwait 2004-2008. Retrieved January, 2015, from http:/www.ibe.unesco.org/National_Reports/ICE_2008/kuwait_NR08.pdf

The International Association for the Evaluation of Educational Achievement. (n. d.). Retrieved November, 2014, from http://www.iea.nl/data.html

Winokur, I. K. (2014). From centralized education to innovation: Cultural shifts in Kuwait's education system. Education for a Knowledge Society in Arabian Gulf Countries (International Perspectives on Education and Society, Vol. 24). Emerald Group Publishing Limited, 24, 103-124. http://dx.doi.org/10.1080/1045988X. 2013.794325

Wiseman, A. W., Alromi, N. H., \& Alshumrani, S. A. (Eds.). (2014). Education for knowledge society in Arabian gulf countries (Vol. 24). Emerald Group Publishing.

\section{Copyrights}

Copyright for this article is retained by the author(s), with first publication rights granted to the journal.

This is an open-access article distributed under the terms and conditions of the Creative Commons Attribution license (http://creativecommons.org/licenses/by/3.0/) 